\title{
Language Issue in German Higher Education Internationalization: Ideologies, Management and Practices for English-Medium Instruction
}

\author{
Xiao Lin ${ }^{1} \&$ Chunchun Yang ${ }^{1}$ \\ ${ }^{1}$ School of International Studies, Zhejiang University, Hangzhou, China \\ Correspondence: Xiao Lin, School of International Studies, Zhejiang University, Hangzhou, China. E-mail: \\ xiaolinzju@163.com
}

Received: June 24, 2020

Accepted: July 27, $2020 \quad$ Online Published: August 6, 2020

doi:10.5539/ijel.v10n6p16

URL: https://doi.org/10.5539/ijel.v10n6p16

\begin{abstract}
Employing document analysis and corpus-assisted discourse analysis, this study examines the language ideologies in German higher education internationalization policies and strategies, across European, German federal and university levels. It further investigates how these policies and strategies relate to the English-medium instruction practices in German universities, adopting Spolsky's $(2004,2009)$ framework for language policy analysis. Results show that all institutions at the three levels recognize the role of EMI in promoting the higher education internationalization, but their policy documents adopt evasive attitudes towards EMI to varying degrees. The internationalization policies at the European level show the most tendency to evade the language issue, especially English, while the German federal internationalization documents include more contents about language, even EMI, and they are concerned about promoting the German language alongside English. At the university level, the welcoming attitudes towards EMI are displayed most overtly in the internationalization strategies and the rapid development trend and the predominant English-only type of EMI programs. The study underscores the potential benefits of a multilayered analysis of higher education internationalization policies and EMI practices, and the universities' important role in balancing the English and the national language in the higher education domain.
\end{abstract}

Keywords: English-medium instruction, Germany, higher education internationalization, language policy and practice, Spolsky

\section{Introduction}

\subsection{The Problem}

With the momentum of globalization, "internationalization has become a central concern in policy discourse surrounding European higher education and figures prominently in various agendas at European, national and university levels" (Wächter, 2008, p.1). The European tertiary sector endeavor to promote the internationalization process in which English-medium instruction (thereafter EMI) plays a predominant role. EMI, "the use of the English language to teach academic subjects in countries or jurisdictions where the first language of the majority of the population is not English" (Dearden, 2014, p. 2), has become a phenomenon spreading rapidly throughout Europe's higher education (thereafter HE) field, the number of identified EMI programs going up from 725 in 2001, to 2,389 in 2007 and 8,089 in 2013 (Maiworm \& Wächter, 2014). In 1996, Germany began to internationalize its HE sector and introduced the pilot EMI program under the auspices of German Academic Exchange Service (hereafter DAAD) and German Rectors' Conference (hereafter HRK) and funded by the German Federal Ministry of Education and Research (hereafter BMBF). In 2002, the pilot program was evaluated and deemed a success. Since then, EMI programs have become a "permanent feature of the German HE landscape" (Witte, 2006, p. 195), and have achieved significant growth in the past over twenty years, with 1,463 EMI programs (DAAD, 2019) across all disciplines. Germany has now become the second largest provider of EMI programs in Europe, closely following the Netherlands.

At the European level, among the many initiatives to promote the internationalization of HE in Europe, the two most influential ones are the Erasmus program launched by the European Commission and the Bologna Process (hereafter BP), a voluntary intergovernmental HE reform initiated with the Bologna Declarations in 1999. The 
BP was designed to harmonise higher education across Europe to promote mobility and to increase the attractiveness of European higher education institutions, which represents the "greatest change European universities have gone through in the past few decades" (Lasagabaster, 2015, p. 260), and the Erasmus program undoubtedly has paved the way for the BP (ibid). The outcomes of the Erasmus program are included in its annual reports, and the BP, its communiqués. At the German federal level, the BMBF, DAAD and HRK together take the responsibility of the management and evaluation for EMI programs. The BMBF is mainly responsible for enacting educational policies at the national level and providing funding, but the practical implementation or supervision is often left to the other two institutions. The DAAD provides various funding, marketing support and prizes to universities that contribute to internationalization. HRK, the union of German universities, functions as the voice of universities in its dialogue with the BMBF. At the university level, the internationalization strategies are drawn up by most German universities, which embed their attitudes towards EMI and reflect the influence of HE internationalization policies at higher levels. But few studies have been carried out to analyze the language consequences that these policy documents at these three levels can result in.

In recent years, EMI policies and practices in HE have become a central aspect of language policy and planning (thereafter LPP) in non-English speaking contexts (Dang et al., 2013). Spolsky's (2004, 2009) framework for language policy analysis has become the most widely-used theoretical framework in EMI studies. However, this topic is underinvestigated in German HE context. This paper fills the gap by reporting on a study which investigates the language ideologies in German higher education internationalization policies and strategies, across European, German federal and university levels, and how these policies and strategies relate to the EMI practices in German universities, adopting Spolsky's framework.

\subsection{Literature Review}

\subsubsection{Spolsky's Framework for Language Policy Analysis}

According to Spolsky's framework for language policy analysis (2004, 2009), language policy comprises three components: language practices, language beliefs and ideology, and language management or planning. Language management refers to "the explicit and observable effort by someone or some group that has or claims authority over the participants in the domain to modify their practices or beliefs" (Spolsky, 2009, p. 4). Language practices refer to "observable behaviors and choices - what people actually do" (ibid). Language ideology refers to "the beliefs about language and language use" (Spolsky, 2004, p. 5).

These three components are not only interrelated but interact with one another in complicated and dynamic ways. First, language ideology derives from and influences language practices (Spolsky, 2004). Second, language ideology provides a basis for, and can be modified by, language management (Spolsky, 2009). Third, language practices provide the linguistic context and instrument for language management and are themselves the target of language management (Spolsky, 2004, 2009). Finally, language management can turn language ideology into language practices. They together make up forces that help account for language choice.

\subsubsection{Internationalization of European HE and EMI}

Many researchers have recognized that internationalization is the key to the survival for higher education institutions (thereafter HEIs) (Costa \& Coleman, 2013), which in turn have contributed to the expansion of English becoming the language of HE par excellence worldwide (Brumfit, 2004). Coleman (2006) argued that the global status of English has impelled its adoption in HE, which would, in turn, advance the internationalization of HE, promoting the growth of English-medium education not only in Europe but also worldwide. Phillipson even pointed out directly that "internationalization in HE has become synonymous with the introduction of EMI programs" (Phillipson, 2008, p. 4). Cots (2013) also pointed out that universities in Europe have crossed the point of no return linguistically in their decision to offer courses, modules and entire degree programs through the medium of English in their attempts to internationalize. That is to say, English plays the role of both the driver and the consequence of the internationalization of European HE.

\subsubsection{Researches on EMI in Germany}

The German EMI researches can be divided into the following three types. The first type is mainly about the benefits and problems that EMI in Germany might cause or have caused (Ammon, 2002; Smit, 2010). The second type is empirical studies, most of which employ the method of questionnaires and (or) interviews to explore the experiences of main stakeholders in the EMI programs (Ammon \& McConnell, 2002; Erling, 2007; Gürtler \& Kronewald, 2015; Dubow \& Gundermann, 2017). The third type employs Spolsky's framework to analyze the influences of the language policies on the language practices at university level. The studies of Hilgendorf (2005), Erling and Hilgendorf (2006) and Earls (2016) have recognized the importance of BP and 
Erasmus as the most influential initiatives and noticed some main policy actors at the German federal level, such as the influence of BMBF, DAAD and HRK's policy documents on EMI, but they have mainly chosen one or some universities to explore the influence and have made no systematic attempt to analyze their institutional language ideologies. Also, the study concerning the interrelationship between these institutional language ideologies and the actual EMI practices in German HEIs in general is lacking.

The present study aims to contribute to this growing literature and extend existing knowledge by taking as its basis Spolsky's framework. Specifically, the study will seek the answers to the following three research questions:

Research question 1: What are the ideologies of HE internationalization policies and strategies at the European, German federal and university levels?

Research question 2: What are the EMI practices at the German university level?

Research question 3: What are the consistencies and discrepancies between the policies and practices in German EMI development?

\section{Methodology}

\subsection{Data Sources}

\subsubsection{Policy Documents at the European Level}

The documents about European internationalization policies were collected from two projects, the BP and the Erasmus/Erasmus+ program. Nine BP communiqués and additionally, the Declaration on the EHEA in 2010 were collected from the EHEA official website (See Table 1). The BP corpus consists of ten texts, which contains 2,251-word types and 22,498-word tokens.

Table 1. List of BP communiqués

\begin{tabular}{|c|c|c|c|}
\hline Number & Year & Publisher & Title \\
\hline 1 & 1999 & $\begin{array}{l}\text { Bologna Ministerial Conferences: Bologna } \\
\text { Declaration }\end{array}$ & $\begin{array}{l}\text { The European higher education area, joint declaration of the European } \\
\text { ministers of education }\end{array}$ \\
\hline 2 & 2001 & Bologna Ministerial Conferences & Towards the European higher education area \\
\hline 3 & 2003 & $\begin{array}{l}\text { Bologna Ministerial Conferences: Berlin } \\
\text { Communiqué }\end{array}$ & $\begin{array}{l}\text { Realising the European Higher Education Area, communique of the } \\
\text { conference of ministers of education. }\end{array}$ \\
\hline 4 & 2005 & $\begin{array}{l}\text { Bologna Ministerial Conferences: Bergen } \\
\text { Communiqué }\end{array}$ & $\begin{array}{l}\text { The European Higher Education Area - } \\
\text { achieving the goals }\end{array}$ \\
\hline 5 & 2007 & $\begin{array}{l}\text { Bologna Ministerial Conferences: London } \\
\text { Communiqué }\end{array}$ & $\begin{array}{l}\text { Towards the European Higher Education Area: Responding to } \\
\text { challenges in a globalised world }\end{array}$ \\
\hline 6 & 2009 & $\begin{array}{l}\text { Bologna Ministerial Conferences: } \\
\text { Leuven/Louvain Communiqué }\end{array}$ & $\begin{array}{l}\text { The Bologna Process 2020-The European Higher Education Area in } \\
\text { the new decade. }\end{array}$ \\
\hline 7 & 2010 & $\begin{array}{l}\text { Bologna Ministerial Conferences: } \\
\text { Budapest-Vienna Declaration }\end{array}$ & Budapest-Vienna declaration on the European Higher Education Area \\
\hline 8 & 2012 & $\begin{array}{l}\text { Bologna Ministerial Conferences: Bucharest } \\
\text { Communiqué }\end{array}$ & $\begin{array}{l}\text { Making the most of our potential: Consolidating the European Higher } \\
\text { Education Area }\end{array}$ \\
\hline 9 & 2015 & $\begin{array}{l}\text { Bologna Ministerial Conferences: Yerevan } \\
\text { Communiqué }\end{array}$ & $\begin{array}{l}\text { The Bologna Process revisited: the future of the European Higher } \\
\text { Education Area }\end{array}$ \\
\hline 10 & 2018 & $\begin{array}{l}\text { Bologna Ministerial Conferences: Paris } \\
\text { Communiqué }\end{array}$ & Paris Communiqué \\
\hline
\end{tabular}

The Erasmus annual reports published by the European Commission were collected (See Table 2). Since the documents about Erasmus before 2005 are not available on the official website, only 14 annual reports of Erasmus and Erasmus ${ }^{+}$program after 2005 were collected in this paper. The Erasmus/Erasmus + corpus consists of 14 texts listed, which contain 6,479-word types and 161,378-word tokens. 
Table 2. List of Erasmus/Erasmus+ Annual Reports

\begin{tabular}{llll}
\hline Number & Year & Publisher & Title \\
\hline 1 & 2005 & European Commission & Erasmus annual report \\
2 & 2006 & European Commission & Erasmus annual report \\
3 & 2007 & European Commission & Erasmus annual report \\
4 & 2008 & European Commission & Erasmus annual report \\
5 & 2009 & European Commission & Erasmus annual report \\
6 & 2010 & European Commission & Erasmus annual report \\
7 & 2011 & European Commission & Erasmus annual report \\
8 & 2012 & European Commission & Erasmus annual report \\
9 & 2013 & European Commission & Erasmus annual report \\
10 & 2014 & European Commission & Erasmus+ annual report \\
11 & 2015 & European Commission & Erasmus+ annual report \\
12 & 2016 & European Commission & Erasmus+ annual report \\
13 & 2017 & European Commission & Erasmus+ annual report \\
14 & 2018 & European Commission & Erasmus+ annual report \\
\hline
\end{tabular}

Four additional documents (See Table 3) were collected from the official website of the Council of Europe, the European Council and European Commission. The Recommendation No. R (96) 7 consists of 2,127-word tokens and 570-word types. The Lisbon Strategy text consists of 1,454-word types and 7,543-word tokens. The Horizon 2020 text consists of 1,251-word types and 5,279-word tokens. The European Higher Education in the World consists of 1,436-word types 6,124-word tokens.

Table 3. Four additional internationalization documents

\begin{tabular}{llll}
\hline Number & Year & Publisher & Title \\
\hline 1 & 1992 & European Communities & Treaty on European Union \\
2 & 2000 & European Council & Lisbon Strategy \\
3 & 2011 & European Commission & Horizon 2020 - The Framework Programme for Research and Innovation \\
4 & 2013 & European Commission & European Higher Education in the World \\
\hline
\end{tabular}

All of the documents listed above were collected between April 2019 and June 2019.

\subsubsection{Policy Documents at the German Federal Level}

At the German federal level, the policy documents related to EMI programs mainly come from three institutions, the BMBF, DAAD, and HRK.

Texts from the BMBF are a total of 6 pieces of reports which consist of the document about the European Year of Language and 5 reports about the internationalization of studies in Germany from 2005 to 2016, downloaded from the BMBF official website (See Table 4). All the documents are written in German and translated by the author. The BMBF corpus contains 6,010-word types and 184,457-word tokens.

Table 4. List of important BMBF documents

\begin{tabular}{lll}
\hline Number & Year & Title \\
\hline 1 & 2001 & European Year of Language 2001 (Europäisches Jahr der Sprachen) \\
2 & 2005 & Internationalization of Studies (Internationalisierung des Studiums) \\
3 & 2008 & Internationalization of Studies (Internationalisierung des Studiums) \\
4 & 2010 & Internationalization of Studies (Internationalisierung des Studiums) \\
5 & 2012 & Internationalization of Studies (Internationalisierung des Studiums) \\
6 & 2016 & Internationalization of Studies (Internationalisierung des Studiums) \\
\hline
\end{tabular}

Data from the DAAD are a total of 10 pieces of annual reports from 2009 to 2018 (See Table 5), downloaded from the DAAD official website. The annual reports before 2009 are not available on the website. All the texts are written in English. The DAAD corpus contains 16,083-word types and 404,789-word tokens. 
Table 5. List of important DAAD documents

\begin{tabular}{lll}
\hline Number & Year & Title \\
\hline 1 & 2010 & DAAD Annual Report of 2009 \\
2 & 2011 & DAAD Annual Report of 2010 \\
3 & 2012 & DAAD Annual Report of 2011 \\
4 & 2013 & DAAD Annual Report of 2012 \\
5 & 2014 & DAAD Annual Report of 2013 \\
6 & 2015 & DAAD Annual Report of 2014 \\
7 & 2016 & DAAD Annual Report of 2015 \\
8 & 2017 & DAAD Annual Report of 2016 \\
9 & 2018 & DAAD Annual Report of 2017 \\
10 & 2019 & DAAD Annual Report of 2018 \\
\hline
\end{tabular}

Texts from the HRK are its annual reports from 2003 to 2016, downloaded from the HRK official website, totally 9 pieces (See Table 6). All the texts are written in English. The HRK corpus contains 9,941-word types and 265,809-word tokens.

Table 6. List of important HRK documents

\begin{tabular}{lll}
\hline Number & Year & Title \\
\hline 1 & 2004 & 2003 Annual Report of HRK \\
2 & 2006 & 2004/2005 Annual Report of HRK \\
3 & 2008 & 2006/2007 Annual Report of HRK \\
4 & 2010 & 2008/2009 Annual Report of HRK \\
5 & 2012 & 2010/2011 Annual Report of HRK \\
6 & 2014 & 2012/2013 Annual Report of HRK \\
7 & 2015 & 2014 Annual Report of HRK \\
8 & 2016 & 2015 Annual Report of HRK \\
9 & 2017 & 2016 Annual Report of HRK \\
\hline
\end{tabular}

Table 7 displays other texts that are important for the analysis of the development of EMI programs in Germany.

Table 7. List of other important documents

\begin{tabular}{|c|c|c|c|}
\hline Number & Year & Publisher & Title \\
\hline 1 & 2000 & BMBF, DAAD \& HRK & $\begin{array}{l}\text { Ten new "foreign-oriented degree programs' selected (Zehn neue "Auslandsorientierte } \\
\text { Studiengänge" ausgewählt)" }\end{array}$ \\
\hline 2 & 2001 & DAAD \& HRK & Evaluation of Internationally Oriented Courses of the Demonstration Program \\
\hline 3 & 2004 & DAAD & $\begin{array}{l}\text { Action Program of the DAAD for the Internationalization of Universities 2004-2010 } \\
\text { (Auf dem Weg zur internationalen Hochschule: Das Aktionsprogramm des DAAD 2004- } \\
\text { 2010) }\end{array}$ \\
\hline 4 & 2006 & DAAD & $\begin{array}{l}\text { Quality Label for the Ten Best International Masters Study Courses at German } \\
\text { Universities }\end{array}$ \\
\hline 5 & 2008 & DAAD & $\begin{array}{l}\text { Quality through Internationalization, the Action program of DAAD 2008-2011(Qualität } \\
\text { durch Internationalität: Das Aktionsprogramm des DAAD 2008-2011) }\end{array}$ \\
\hline 6 & 2009 & HRK \& DAAD & National Code of Conduct on Foreign Students at German Universities \\
\hline
\end{tabular}

\subsubsection{Policy Documents at the University Level}

The internationalization strategies were downloaded manually from the official websites of all the 171 German universities that have introduced EMI programs. The number and types of EMI programs and language requirements for admission were collected through searching their official websites. All these data were collected between May and July 2019. But it needs to be clarified that the website of a university may include much information about internationalization, so the criterion to select the texts is what included in its Internationalization Strategy, or depicted in the International Profile (if Internationalization Strategy is not available). Altogether, the corpus of internationalization strategies or international profiles of 171 universities contains 9,606-word types and 211,744-word tokens. 


\subsubsection{Language Practices at the University Level}

Language practices refer to the overall development of EMI programs in Germany, including the data about the number, types and language requirements for admission. These data were collected from the three most comprehensive investigations about European EMI by far, prepared by the Academic Cooperation Association (ACA) (Maiworm \& Wätcher, 2002, 2008, 2014) and the DAAD official website.

\subsection{Methods}

Document analysis and corpus-assisted discourse analysis were adopted in this paper to analyze the collected data. Documents of all types that "help the researcher uncover meaning, develop understanding, and discover insights relevant to the research problem" can be the sources of analysis (Merriam, 1988, p. 118). In this paper, the documents consist of the policy documents, annual reports, Communiqués and internationalization strategies. The corpus analysis toolkit AntConc3.2.4w developed by Laurence Anthony was also used to analyze the collected data. This paper mainly employed this toolkit's function of keywords, collocates and concordance plot. In this paper, the concordance hits and concordance keyness of "English", "language/linguistic" and "multilingual(ism)/plurilingual(ism)" of the documents of the three levels were analyzed. And the collocation analysis tool was used to ascertain how these words are used. Also, the data collected about the number and types of EMI programs as well as the English and German requirements for admission were analyzed through descriptive statistical analysis.

\section{Data Analysis and Results}

\subsection{Mobility-Led European Internationalization Policies}

The language issue does not form a great concern in the European internationalization documents. In the BP documents, "European higher education" appears 122 times and "mobility" 103 times, while "language/linguistic" is mentioned 4 times, "multilingualism" only once and "English" not mentioned at all. The Erasmus documents mention "language" 143 times, "English" 24 times and "multilingual(ism)" 13 times. By contrast, "higher education" appears 835 times and "staff/student mobility" 732 times. Thus, the BP and the Erasmus documents are clearly about the HE internationalization. The internationalization of European HE began in terms of legislation in 1992 through the Treaty on European Union, which stimulated the cooperation between the HEIs of European countries: "the Community shall contribute to the development of quality education by encouraging cooperation between Member States by supporting and supplementing their action". From the economic perspective, the HEIs are described by the Lisbon Strategy as the chief engine of Europe's becoming "the most dynamic and competitive knowledge-based economy in the world by 2010 capable of sustainable economic growth".

Through further document analysis, it's found that mobility promotion has been regarded as an essential strategy for pursuing internationalization and language issue does not play a prominent role in European institutions' coping with the HE internationalization. Mobility promotion has been associated with promoting HE quality, personal development and employability, linguistic pluralism and cooperation and competition. The following extract from Leuven/Louvain Communiqué (2009) illustrates mobility and internationalization are explicitly linked within the discourse of European higher education:

We believe that mobility of students, early stage researchers and staff enhances the quality of programmes and excellence in research; it strengthens the academic and cultural internationalization of European higher education. Mobility is important for personal development and employability, it fosters respect for diversity and a capacity to deal with other cultures. It encourages linguistic pluralism, thus under- pinning the multilingual tradition of the European Higher Education Area and it increases cooperation and competition between higher education institutions. Therefore, mobility shall be the hallmark of the European Higher Education Area (Leuven/Louvain Communiqué, 2009).

Thus, in the European internationalization policies, the language issue is rarely made explicit reference to, revealing that European institutions, in general, show little explicit concern about language issues in the context of HE internationalization.

\subsection{Language Policies at the German Federal Level}

EMI is seldom mentioned in the policy documents at the European level, but it is much more common in the texts at the German federal level. "English" and "language/linguistic" are not uncommon in these documents and, occurring 266 and 498 times respectively while the occurring frequency of "multilingual(ism)/plurilingual(ism)" is much lower (28). Still, discrepancy exists among the three institutions. Compared with the DAAD and BMBF, the HRK is much more evasive about EMI, devoting fewer lines to EMI-related issues in its annual reports. 
Though the concordance hits of "English" in its annual reports are 75, it is interesting to notice that 62 of them come from the same document (2010-2011 Annual Reports), while the rest of the documents contain only 13 hits. The result showed that there are totally 53 sentences that have mentioned EMI, and 26 of them have equaled EMI with internationalization, 15 of them high quality, and 17 of them have mentioned the negative influence of EMI on the German language. Further document analysis of such discourse will be displayed below.

\subsubsection{EMI Promotes Internationalization}

According to the Evaluation of Internationally Oriented Courses of the Demonstration Program published by the DAAD and HRK, the aim of introducing EMI programs is to "test the potential of EMI programs to foster internationalisation in the HE sector" (DAAD \& HRK, 2001, p. 2). After the introduction of EMI programs, courses in English are depicted by the BMBF as one of "the most important elements" (BMBF, 2005, p. 5) for attracting international students, thus establishing the close relationship between EMI and HE internationalization. Similarly, the Action Program of the DAAD for the Internationalization of Universities also points out that "EMI program is a central component in stimulating and driving internationalization in the German HE system" (DAAD, 2002, p. 1), and also explicitly defines internationalization as synonymous with the introduction of EMI programs (ibid). Though EMI is seldom mentioned in the HRK annual reports, it is implicitly referred to in the statements about internationalization or mobility promotion. For instance, the outlook statement of the HRK in 2013 expresses its commitment to "internationalization of German universities", "continuous international exchange" and "internationalization [...] in dialogue with our partners worldwide" (HRK, 2013, p. 4), all of which will indirectly foster EMI, considering the need for a shared language for communication in these activities.

\subsubsection{EMI Equals High HE Quality}

The ideology of equaling EMI with high HE quality can be found in the EMI discourse. For example, the BMBF 2008 report emphasizes that:

Building world-class universities of $\mathrm{HE}$ requires more efforts of universities in their process to Internationalisation, [...] and the highly sought-after English language courses can be expanded for attracting more international students (BMBF 2008, p. 2).

According to this extract, EMI programs can not only attract international students, but also are important for German HEIs to excel in the global HE field. Similarly, the DAAD annual report of 2011 mentions the contribution of EMI:

This put Germany in third place - behind Canada and the UK — on the list of countries where American students have gone abroad to pursue full-time study. These positive developments can be attributed to successful marketing on the part of German universities and the expansion of their English-based degree programmes (DAAD, 2011, p. 62).

It can be found from the extract that the large admission of American students symbolizes the excellence of the host country, which is attributed to the EMI programs.

\subsubsection{EMI Hampers German Language}

With the increasing importance of English in the domain of German HE, institutions at the federal level realize that EMI can hamper German language as the academic language, which can be found in DAAD's 2010 annual report:

The best way to promote German as an academic language, is academic excellence at German higher education institutions. Study programmes in English ought to offer more German modules alongside the courses in order to boost the social integration of the foreign guests at institutions (DAAD, 2010, p. 39).

This statement sets demands on EMI programs, emphasizing the importance of German language study alongside English, so as to promote the status of German. This can reveal DAAD's intention to protect the status of German in the academic field.

Similarly, the HRK is also concerned about the German language issue in EMI programs. For example, the Code of Conduct issued by the HRK (HRK, 2009) requires the universities provide German language courses both before and during students' study in EMI programs, or information about German language training for students. The 2011 annual report of HRK makes a detailed description of the Language Policy for German Universities:

To promote multilingualism and to ensure that German remains a language of science and scholarship, there needs to be a reflective approach to decisions pertinent to language policy (HRK, 2011, p. 58). 
It goes on to urge the EMI programs to set German language qualifications for international students or integrate German language learning as the "mandatory components" (HRK, 2011, p. 64) of the EMI programs and to set the language learning objectives for the students.

\subsection{Language Practices at the University Level}

\subsubsection{Increasing Numbers of EMI Programs}

Since the pilot program initiated in 1996, EMI programs in Germany have undergone continued growth (see Figure 1). In 2002, only 65 EMI programs were introduced in Germany while in 2008 the number is 214, a three-fold increase is identifiable. Then in 2009, 505 EMI programs are recorded by the DAAD. According to the most recent statistics (DAAD 2018), the total number of EMI programs in Germany is 1,137.

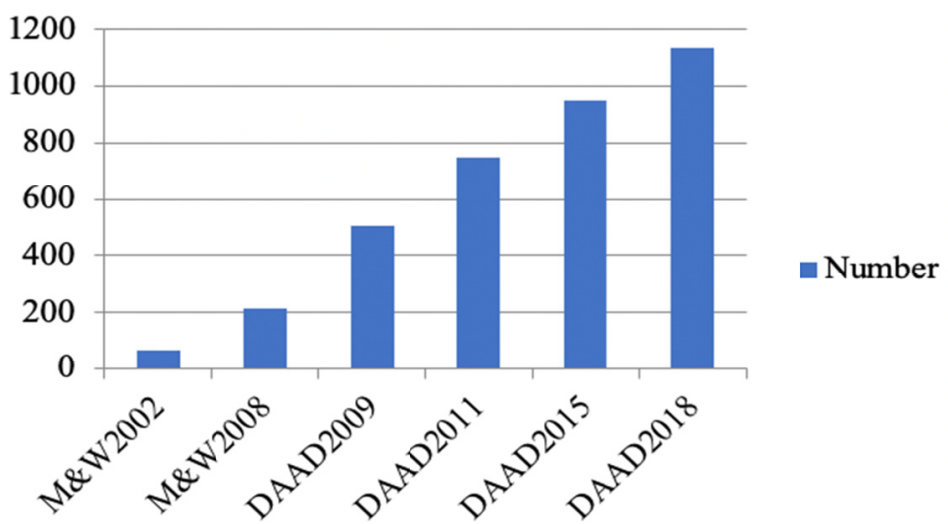

Figure 1. Numbers of EMI programs offered in Germany

\subsubsection{Types of EMI Programs}

Currently, there are three types of EMI programs in German HEIs. The first and dominant one is the "English-only" type, where courses are taught exclusively in English, so knowledge of German is not required either before or during the study in such programs. In 2018, The "English-only" type accounts for 1,012 of the 1,137 DAAD-accredited EMI programs. The rest is the German-English programs, with both German and English being used as the language of instruction. This kind of programs accounts for the remaining 125 of the 1,137 EMI programs in 2018. It is noteworthy that there are two types of German-English programs: the phased English-to-German model, where students begin the studies in English and are then taught entirely in German after their intensive accelerated studies of German language; and the English-and-German model where both languages are used in parallel as the media of instruction.

\subsubsection{Language Requirements for Admission}

According to the collected data from 1,463 EMI programs in Germany, almost all programs have set English language requirements for applicants. Moreover, more than 88 percent of these EMI programs have made specific requirements for English proficiency. The admission requirements for English are sometimes described through different official assessments of English proficiency, including the Common European Framework Reference (CEFR) for Languages, the TOEFL test, the IELTS test, the Cambridge Certificate (CAE) and the Cambridge Certificate of Proficiency in English (CPE). Thus, for better comparability, the English requirement of each program was manually converted to IELTS scores according to the conversion chart drawn by the Educational Testing Service (ETS). The final result showed that the average English requirement of all the EMI programs is 6.19 of the IELTS, while the average requirement of the master programs is 6.23 , higher than that of the bachelor programs (6.03).

In comparison, the German language requirements for admission are much less mentioned. Only $12 \%$ of EMI programs have set strict requirements for German proficiency alongside English, despite that they mostly require only the basic knowledge (CEFR level A1). Moreover, more than $28 \%$ of EMI programs do not require but rather recommend a command of the German language in the language requirement column.

\subsubsection{Universities' Internationalization Strategies}

The corpus tool was employed first to find out the frequency of "English", "language/linguistic" and 
"multilingual(ism)/plurilingual(ism)" in the internationalization strategies or international profiles of all of the 171 universities (see Table 8). The result showed that 119 of them have mentioned "English", the total concordance hits of which add up to 336. And 125 of them have mentioned "language/linguistic", the total concordance hits adding up to 1,072 . In contrast, the concordance hits of "multilingual(ism)/plurilingual(ism)" are only 25 , significantly lower than those of "English" and "language/linguistic". Then, the collocation tool was used to find out the collocations of the three words, the collocations of each with the top 5 highest frequency are also listed in Table 8, but the collocations of "multilingual(ism)/plurilingual(ism)" are too few to generate any result, with all collocations occurring only once.

Table 8. Concordance hits and total plots of English, language and multilingualism

\begin{tabular}{lllll}
\hline Words & Concordance hits & Concordance plots & Top Collocations & Frequency \\
\hline English & 336 & 119 & language & 90 \\
& & German & 56 \\
& & courses & 52 \\
& & taught & 50 \\
& & & international & 43 \\
Language & \multirow{2}{*}{125} & courses & 143 \\
& & & German & 90 \\
& & English & 90 \\
& & foreign & 81 \\
Multilingual(ism)/ & 25 & & skills & 79 \\
plurilingual(ism) & & All collocations occur once only \\
\hline
\end{tabular}

The common collocations of "English" in the internationalization documents of these 171 universities include "language", "German", "courses", "taught", and "international". The common collocations of "language" include "courses", "German", "English", "foreign" and "skills". It can be found that "English language" enjoys equal concordance hits with "German language". However, some HEIs construe English as "foreign language" instead. Then among the 56 collocations of "English" with "German", more than 91 percent of them are presented in the form of coordinating relations, e.g. German and/or English. It can be revealed from such data that the universities have tried to expand the use of German in EMI programs, in response to the ideology of protecting the German language at the federal level.

Moreover, EMI can find its expressions in the form of "English-taught programs/courses" or "English-language courses/programs". Thus, these collocations were searched to analyze the contexts. Altogether, there are 210 concordance hits of such expressions, among which 169 are mentioned by the universities as a strategy of attracting international students and staff, 104 are mentioned as a strategy of sharpening the international profile of the university, and 87 are described as important for HE quality improvement. EMI is valued by more than $70 \%$ of the 119 German HEIs as a strategy to promote the international attractiveness of the universities. For instance, the University of Potsdam states:

To make the University of Potsdam increasingly attractive for international students, we intend to offer more English-language lectures and seminars, new English-language Master programs, dual-degree programs, and fast-track doctoral procedures (University of Potsdam, 2015, p. 2).

More than $60 \%$ of German HEIs hold the view that EMI can sharpen their international profile. For instance, the strategy of the University of Regensburg states:

Double Degree programs, English taught Master programs, as well as degree programs with a strong international focus, enhance the international profile of UR (University of Regensburg, 2018, p. 1).

More than $63 \%$ of the universities believe that EMI programs are equal to high quality. For instance, the University of Münster states that it is the University's aim to achieve a top position amongst the world's leading universities through:

English-taught programmes as well as degree courses which are offered in cooperation with partner universities abroad (University of Münster, 2012, p. 2).

\subsection{Policy-Practice Interface}

Consistencies and discrepancies can be found in the discourses about "English", "language/linguistic" and 
"multilingual(ism)/plurilingual(ism)". The advocation of EMI is shared in the ideologies/attitudes at these three levels, which can be verified by the discussions about ideologies at each, displayed in the preceding section. However, similar attitudes towards EMI are embedded in different discourses, which also make some differences. The concordance hits and keyness of "English", "language/linguistic" and "multilingual(ism)/plurilingual(ism)" in documents at these three levels are displayed in Table 9.

Table 9. Concordance hits and keyness of language-related words at three levels

\begin{tabular}{lllll}
\hline Level & & European & Federal & University \\
\hline Word Counts & & 183,876 & 855,005 & 211,744 \\
Language & Concordance hits & 147 & 498 & 1,072 \\
& keyness & 710 & 3,197 & 7,801 \\
English & Concordance hits & 24 & 266 & 336 \\
& keyness & 29 & 683 & 1,364 \\
Multilingual(ism) & Concordance hits & 14 & 28 & 25 \\
& Keyness & 130 & 191 & 159 \\
\hline
\end{tabular}

The texts of European internationalization policies contain 183,876-word tokens and the concordance hits of the word "English", "language/linguistic" and "multilingual(ism)/plurilingual(ism)" are 147, 24 and 14, with the keyness of 710, 29 and 130. Distinctions are found between internationalization documents at different levels. In comparison, the keyness of "language/linguistic" and "English" are significantly lower in European policy texts than those at the other two levels, while that of "multilingual(ism)/plurilingual(ism)" is generally the same. The keyness of both "language" and "English" decreases from the European level to the federal and university levels. But "language" has the highest keyness at the German federal level while "English", the university level. It indicates that the language issues are more overtly mentioned at the German federal level while the universities tend to focus directly on the more specific "English" issue. In general, in the context of HE internationalization, European institutions show least concern about language issues, while the German federal institutions, in practical implementation of internationalization, give more attention to language issues, but relatively abstract, and the universities concentrate more on the specific "English" language issues, and even "EMI", whose synonymous expressions appear 210 times at the university level.

\section{Discussion}

The data analysis results suggest that the policies and practices towards EMI have revealed the institutional language ideologies at different levels both explicitly and implicitly. Language issues do not feature in European mobility-led internationalization policies. In light of the ideology of equaling mobility as HE internationalization and high HE quality, EMI development has been implicated in the mobility discourse. BMBF, DAAD and HRK have generally agreed that EMI is one of the primary means for HE internationalization and high HE quality, thus enhancing the competitiveness of its tertiary education in the global arena. EMI hampering German language promotion has also been acknowledged in its discourse. Universities' attitudes towards English are predominantly positive and the introduction of EMI programs is equal to international attractiveness, international profile of the universities and high HE quality. The five-fold increase (from 214 in 2008 to 1,463 in 2019) in the number of EMI programs in the past decade and the predominant English-only type of EMI programs can also demonstrate the German HEIs' welcoming attitudes towards EMI programs.

Thus, these three levels are consistent in recognizing the positive roles that EMI plays in developing HE internationalization with high $\mathrm{HE}$ quality. But the discourses at three levels mention language-related issues and EMI with different extent of implication. It indicates that the internationalization policies at the European level show the most tendency to evade the language issue, especially English, while the German internationalization documents include more contents about language and even EMI, construing English as "foreign language" can also be found, and they are concerned about promoting German language alongside English. At the university level, the welcoming attitudes towards EMI are displayed most overtly in the internationalization strategies and the development trend of EMI programs. The results of this study are in line with the previous multilayered studies in that discrepancies exist between different levels (e.g., Halonen, Ihalainen, \& Saarinen, 2014; Soler-Carbonell, Saarinen, \& Kibbermann, 2017).

On the surface, the BP is not directly related to language, but its implementation requires a lingua franca in the field of education in order to achieve mobility, which solidifies the importance of English among the transnational and cross-language flow of international students (Rose \& Galloway, 2019, p. 194). The higher 
education internationalization policies of the $\mathrm{EU}$ and other supranational institutions are not specific to language, but they in fact function as implicit language policies (Piller \& Cho, 2013; Ljosland, 2014; Saarinen, 2014; Macaro et al., 2019). They have a "trickle-down" effect on the EMI policies and practices at the level of European states and universities. Costa and Coleman (2013) even think that the Bologna process has practically resulted in the Englishization of the curriculum, which has undermined the policy objective of European multilingualism or the "mother tongue plus two other languages", thus leaving little room for foreign languages other than English.

The European states used to shoulder the sole responsibilities for national education policies, but since the beginning of the 21 st century, in response to the acceleration of globalization and internationalization, the supranational policymaking at the European level has become increasingly important. The Bologna Process is a case in point. Yet European states are different significantly in cultures and structures, the national states have to engage with the local interpretation of those European initiatives and give more explicit guidelines as regards the English language and the national language specific to their circumstances.

Also, universities are increasingly reacting to market forces rather than only to national initiatives and they face more implementation problems in language issue. German universities have set up EMI programs not only for international mobility programs, but also the overall trend of globalization and internationalization. Because of this trend, English has established itself as the most used language in lingua franca context (Crystal, 1997; Graddol, 1997) and the dominant language for international communication (Graddol, 1997; Seidlhofer et al., 2009). In the German context, as is the case in the rest of Europe, English has permeated into nearly all domains of German society. According to the report from Education First which investigated English proficiency of adults in more than 100 non-English speaking countries/regions, Germany ranks at the highest band of "very high proficiency" (Education First, 2019). According to the report of Federal Bureau of Statistics in Germany (2018), in the 2016-2017 school year, around 7.2 million primary and secondary students learned English in Germany, which corresponds to $86 \%$ of the total student population, whereas only $17.6 \%$ learned French, the second most widely learned language. Thus, it's quite natural for universities in Germany to adopt English as the teaching medium. Germany, and the other non-English-speaking European countries are undertaking a process of introducing EMI as a means of overcoming any competitive disadvantage resulting from their linguistic situation (Maiworm \& Wächter, 2008, p. 15).

From the policy documents analyzed in this paper, a key emerging sociolinguistic concern is how to balance between the status and use of the English language and the German language. The relationship between the English language and the national language has always been a concern among scholars (e.g., Björkman, 2013; Lasagabaster, 2015). The heart of the question seems to be that universities are regarded by many as the guarantors of the maintenance and development of national cultures and languages, though at the same time they are expected to operate and be competitive on an international scale (Cots, Lasagabaster, \& Garrett, 2012). As seen from the analysis, the European and German federal levels have increasingly emphasized the important role universities can play in balancing the English language and the national language, and promoting linguistic diversity. Actually, EMI originated in the European ideal of plurilingual competence for EU citizens, and the European language policies of multilingualism or linguistic diversity, which is held to be vital both for the inheritance of European cultural assets and personal development of European citizens. The European Action Plan 2004-2006 specifies that higher education institutions play a key role in promoting societal and individual multilingualism (European Commission, 2004, p. 8). In the report of the European Higher Education in the World, the European Union urges universities to balance the dominance of English and promote multilingualism at the university level (European Commission, 2013). In Bologna Process 2020, linguistic diversity is the expected outcome of the higher education internationalization. Thus, universities have been increasingly aware of their importance of carrying out their own language planning at the university level.

\section{Conclusion and Implications}

Employing document analysis and corpus-assisted discourse analysis, this study has examined the management, ideologies and practices for EMI in German higher education internationalization, across European, German federal and university levels, adopting Spolsky's $(2004,2009)$ framework. Results have shown that the German EMI development has been shaped by the joint forces of activities at the level of European, German federal and university levels.

The present study has the following implications. Theoretically, Spolsky's tripartite framework can provide a useful analytic perspective on the interrelationship between policies and practices in the study of EMI programs in German HE. This study has shown that the language management, practices and ideology are analytically 
distinct, yet interconnected and interdependent. Also, the multi-layered examination of these three dimensions at European, German federal and university levels illuminates the real EMI phenomenon in Germany, which can contribute to the illumination of the connections across the various levels of LPP, the "perennial challenge" (Hult, 2010) for the LPP field.

Practically, while this study focuses on the EMI situation in German HE, the results certainly have implications for other contexts, where English is being used increasingly as the teaching medium. It's widely acknowledged that globalization has prompted a wide range of policy borrowing in the field of higher education globally (Rizvi \& Lingard, 2010), and the prevalence of EMI programs in German universities is a good example. But globalization is not a top-down homogenization of politics and cultures, education policies resulting from globalization is reinterpreted and reconstructed through the educational structure at the national and local levels. To international universities, they have to balance the demands of globalization and internationalization and their own interests, which is not an easy task. Especially at present there is a simple understanding of equaling HE internationalization with EMI and a lack of deep understanding of the real meaning of HE internationalization, much work is necessary at multiple levels in order to create a space that can more fully support the potential of sound EMI development in the higher education sector.

This study also has some limitations which can be improved in future studies. Firstly, this study fails to gather all documents needed to explore the interrelationship among BMBF, HRK and DAAD. The absence of annual reports of the DAAD before 2009 makes the analysis about the development of the DAAD and its longitudinal comparison with the BMBF and the HRK less enlightening. Secondly, this study has failed to analyze the EMI data in a stratified fashion, for example, domestic $v s$. international students, which can be improved in the future. Finally, because of the practical limitation, this study hasn't collected stakeholders', such as teachers' and students' attitudes towards EMI through questionnaires and interviews, which can be conducted to get a fuller picture of the language practices.

\section{Acknowledgements}

This study has been supported by Zhejiang University Teaching and Reserach Development Project for Liberal Arts Faculty (Project No. 106000-541903/106).

\section{References}

Ammon, U., \& McConnell, G. (2002). English as an academic language in Europe: A survey of its use in teaching. Bern: Peter Lang.

Björkman, B. (2013). English as an academic lingua franca: An investigation of form and communicative effectiveness. Berlin/New York: De Gruyter Mouton. https://doi.org/10.1515/9783110279542

Brumfit, C. J. (2004). Language and higher education: Two current challenges. Arts and Humanities in Higher Education, 3(2), 163-173. https://doi.org/10.1177/1474022204042685

Coleman, J. A. (2006). English-medium teaching in European higher education. Language Teaching, 39, 1-14. https://doi.org/10.1017/S026144480600320X

Costa, F., \& Colemanm, J. (2013). A survey of English-medium instruction in Italian higher education. International Journal of Bilingual Education and Bilingualism, 16(1), 3-19. https://doi.org/10.1080/13670050.2012.676621

Cots, J. M. (2013). Introducing English-medium instruction at the university of Lleida, Spain: intervention, beliefs and practices. In A. Doiz, D. Lasagabaster \& J. M. Sierra (Eds.), English-medium instruction at universities (pp. 106-130). Bristol: Multilingual Matters. https://doi.org/10.21832/9781847698162-010

Cots, J. M., Lasagabaster, D., \& Garrett, P. (2012). Multilingual policies and practices of universities in bilingual regions in Europe. International Journal of the Sociology of Language, 216, 7-32. https://doi.org/10.1515/ijsl-2012-0037

Crystal, D. (1997). English as a global language. Cambridge: Cambridge University Press.

DAAD—Deutscher Akademischer Austausch Dienst. (2019). Annual report of the German Academic Exchange Service 2018. Bonn: DAAD.

Dang, T. K. A., Nguyen, H. T. M., \& Le, T. T. T. (2013). Impacts of globalization on EFL teacher education through English as a medium of instruction: An example from Vietnam. Current Issues in Language Planning, 14(1), 52-72. https://doi.org/10.1080/14664208.2013.780321

Dearden, J. (2014). English as a medium of instruction - A growing global phenomenon: Phase 1. Interim Report 
April 2014. Retrieved from https:// www.britishcouncil.org/education/ihe

Dubow, G., \& Gundermann, S. (2017). Certifying the linguistic and communicative competencies of teachers in English-medium instruction programmes. Language Learning in Higher Education, 7(2). https://doi.org/10.1515/cercles-2017-0021

Earls, C. W. (2016). Evolving agendas in European English-medium higher education. London: Palgrave Macmillan. https://doi.org/10.1057/9781137543127

Education First. (2019). EF English Proficiency Index. Retrieved from https://www.ef.edu/epi/regions/europe/

Erling, E. J. (2007). Local identities, global connections: Affinities to English among students at the Freie Universität Berlin. World Englishes, 26(2), 111-130. https://doi.org/10.1111/j.1467-971X.2007.00497.x

Erling, E. J., \& Hilgendorf, S. K. (2006). Language policies in the context of German higher education. Language Policy, 5(3), 267-293. https://doi.org/10.1007/s10993-006-9026-3

European Commission. (2004). Promoting language learning and linguistic diversity: An action plan 2004-2006. Brussels: European Commission.

European Commission. (2013). European higher education in the world. Retrieved from http://eurlex.europa.eu/legalcontent/EN/TXT/PDF/?uri= CELEX:52013D C0499\&from=EN

Federal Bureau of Statistics in Germany. (2018). Schulen auf einen Blick 2018. Wiesbaden: Statistisches Bundesamt.

Graddol, D. (1997). The future of English? London: British Council.

Gürtler, K., \& Kronewald, E. (2015). Internationalization and English-medium instruction in German higher education. English-Medium Instruction in European Higher Education, 4(2), 89-114. https://doi.org/10.1515/9781614515272-006

Halonen, M., Ihalainen, P., \& Saarinen, T. (2014). Language policies in Finland and Sweden: Interdisciplinary and multi-sited comparisons. Bristol: Multilingual Matters. https://doi.org/10.21832/9781783092710

Hilgendorf, S. K. (2005). Brain gain statt [instead of] brain drain: The role of English in German education. World Englishes, 24(1), 53-67. https://doi.org/10.1111/j.0883-2919.2005.00387.x

Hult, F. M. (2010). Analysis of language policy discourses across the scales of space and time. International Journal of the Sociology of Language, 202, 7-24. https://doi.org/10.1515/ijsl.2010.011

Lasagabaster, D. (2015). Language policy and language choice at European Universities: Is there really a "choice"? International Journal of Applied Linguistics, 3(2), 255-276. https://doi.org/10.1515/eujal-2014-0024

Ljosland, R. (2014). Language planning confronted by everyday communication in the international university: the Norwegian case. Journal of Multilingual \& Multicultural Development, 35(4), 392-405. https://doi.org/10.1080/01434632.2013.874436

Macaro, E., Hultgren, A. K., Kirkpatrick, A., \& Lasagabaster, D. (2019). English medium instruction: Global views and countries in focus: Introduction to the symposium held at the Department of Education, University of Oxford on Wednesday 4 November 2015. Language Teaching, 52(2), 231-248. https://doi.org/10.1017/S0261444816000380

Maiworm, F., \& Wächter, B. (2002). English-language-taught degree programmes in European higher education: Trends and success factors. Bonn: Lemmens.

Maiworm, F., \& Wächter, B. (2008). English-language-taught degree programmes in European higher education. Bonn: Lemmens.

Maiworm, F., \& Wächter, B. (2014). English-language-taught degree programmes in European higher education: The state of play in 2014. Bonn: Lemmens.

Merriam, S. B. (1988). Case study research in education: A qualitative approach. San Francisco: Jossey-Bass.

Phillipson, R. (2008). Lingua franca or lingua frankensteinia? English in European integration and globalisation. World Englishes, 27(2), 250-284. https://doi.org/10.1111/j.1467-971X.2008.00555.x

Piller, I., \& Cho, J. (2013). Neoliberalism as language policy. Language in Society, 42(1), 23-44. https://doi.org/10.1017/S0047404512000887

Rizvi, F., \& Lingard, B. (2010). Globalizing education policy. New York, NY: Routledge. 
https://doi.org/10.4324/9780203867396

Rose, H., \& Galloway, N. (2019). Global Englishes for language teaching. Cambridge: Cambridge University. https://doi.org/10.1017/9781316678343

Saarinen, T. (2014). Language ideologies in Finnish higher education in the national and international context: A historical and contemporary outlook. In A. K. Hultgren, F. Gregersen \& J. Thøgersen (Eds.), English in Nordic universities: Ideologies and practices (pp. 127-146). Amsterdam: John Benjamins. https://doi.org/10.1075/wlp.5.06saa

Seidlhofer, B., Breiteneder, A., \& Pitzl, M. (2009). English as a lingua franca in Europe: An empirical perspective. World Englishes, 28(2), 256-269. https://doi.org/10.1111/j.1467-971X.2009.01579.x

Smit, U. (2010). English as a lingua franca in higher education: a longitudinal study of classroom discourse. New York: De Gruyter.

Soler-Carbonell, J., Saarinen, T., \& Kibbermann K. (2017). Multilayered perspectives on language policy in higher education: Finland, Estonia, and Latvia in comparison. Journal of Multilingual and Multicultural Development, 38(4), 301-314. https://doi.org/10.1080/01434632.2016.1198356

Spolsky, B. (2004). Language policy. New York: Cambridge University Press.

Spolsky, B. (2009). Language management. Cambridge: Cambridge University Press.

University of Münster. (2012). The University of Münster internationalisation strategy 2012-2018. Retrieved from

https://www.unimuenster.de/imperia/md/content/wwu/auslandsamt/pdf/internationlisierung/internationalisie rungsstrategie_wwu_en_2018.pdf

University of Potsdam. (2015). Internationalization strategy of the University of Potsdam 2015-2019. Retrieved from http://www.unipotsdam.de

University of Regensburg. (2018). Internationalization. Retrieved from http://www.uni-regensburg.de

Wächter, B. (2008). Internationalisation and the European Higher Education Area, accepted for Bologna 2020: Unlocking Europe's potential-Contributing to a better world. Retrieved from http://193.190.148.151/hogeronderwijs/bologna/BolognaSeminars/documents/Ghent/Ghent_May08_Bernd _Waechter.pdf

Witte, J. (2006). Change of degrees and degrees of change. Unpublished paper (PhD), Universiteit Twente: CHEPS.

\section{Copyrights}

Copyright for this article is retained by the author, with first publication rights granted to the journal.

This is an open-access article distributed under the terms and conditions of the Creative Commons Attribution license (http://creativecommons.org/licenses/by/4.0/). 